LETTERS TO THE EDITOR

If you have a burning desire to respond to a paper published in Thorax, why not make use of our "rapid response" option? Log on to our website (www.thoraxjnl.com), find the paper that interests you, and send your response via email by clicking on the "eletters" option in the box at the top right hand corner.

Providing it isn't libellous or obscene, it will be posted within seven days. You can retrieve it by clicking on "read eletters" on our homepage.

The editors will decide as before whether to also publish it in a future paper issue.

\section{Sleep disordered breathing in an adult with cherubism}

Cherubism is a rare disorder with bilateral enlargement of the mandible that regresses with time. Bone degrading osteoclasts and bone building osteoblasts function abnormally causing the changes. It is an autosoma dominant condition which manifests in early childhood by the age of 2-5 years, but late regresses with time. Airway obstruction occurs due to backward displacement of the tongue affecting respiration.

An 18 year old male was referred to us for snoring. On inquiry the mother reported swelling of the lower face since childhood, which had progressed to its present size. The patient had difficulty in speech, mastication and swallowing with mental retardation. There was a history of excessive daytime som nolence, nocturia, and increased irritability during the previous few years. On examination he had characteristic features of cherubism. The lower eyelids were retracted and his oral examination revealed gingival hypertrophy with most of the upper and lower teeth embedded in the gums. The tongue was enlarged and the posterior pharyngeal wal could not be visualised. Fine needle aspiration biopsy of the mandible revealed the presence of giant cells with fibrous tissue. A diagnostic record of night time recording of respiratory variables was performed which showed the presence of snoring and an apnoea/ hypopnoea index (AHI) of 12/hour associated with oxygen desaturation. A second study was performed with nasal continuous positive airway pressure (CPAP) of $7 \mathrm{~cm} \mathrm{H} \mathrm{H}_{2} \mathrm{O}$, following which AHI reduced to 3/hour with no oxygen desaturation or snoring. Obstructive sleep apnoea has been reported only once earlier in a 5 year old boy who was treated with tracheostomy. ${ }^{1}$ This is the second report associating cherubism with obstructive sleep apnoea and mental retardation, and the first report of an adult who responded to CPAP therapy.

S Ladhani, P Sundaram, J M Joshi

Department of Respiratory Medicine, TN Medical College and B Y L Nair Hospital, Mumbai, India
Correspondence to: Dr J M Joshi, Department of Respiratory Medicine, T N Medical College and B Y L Nair Hospital, Mumbai-400008, India deptrespmed@hathway.com

Reference

1 Battaglia A, Merati AL, Magit A. Cherubism and upper airway obstruction. Otolaryngol Head and Neck Surg 2000;122:573-4.

\section{Sarcoidosis presenting as upper extremity venous thrombosis}

Sarcoidosis is a multisystem granulomatous disorder of unknown aetiology which is characterised pathologically by the presence of non-caseating granulomas. Typical presenting symptoms include cough and dyspnoea in addition to skin and/or eye lesions. We report a case of sarcoidosis presenting as upper extremity venous thrombosis.

A 39 year old woman presented with sudden swelling of the right upper limb and right side of the neck and face. She reported no cough, dyspnoea, chest pain, or systemic symptoms of fever or weight loss. She had no previous medical history, smoked 20 cigarettes daily, and was on an oral contraceptive pill (levonorgestrel, Schering Health Care Ltd). On examination her body mass index was 31. She had extensive swelling of the right upper limb and right side of the neck and face. Her upper limb pulses were normal and she had no palpable lymphadenopathy. Full blood count, coagulation screen, electrolytes, renal function indices, and serum angiotensin converting enzyme levels were normal. Liver function tests and fasting cholesterol were mildly raised. Serum calcium and 24 hour urinary calcium levels were normal. Pulmonary function testing revealed normal spirometric parameters (FEV, 2.32 litres (85\% predicted), FVC 2.97 litres (93\% predicted) reduced carbon monoxide transfer factor a $15.7 \mathrm{mmol} / \mathrm{min} / \mathrm{mm} \mathrm{Hg} / \mathrm{l}$ (62\% predicted)). A plain chest radiograph showed slight widening of the superior mediastinum, and a computed tomographic (CT) scan showed thrombosis of the right brachiocephalic vein with enlargement of the axillary and mediastinal lymph nodes (fig 1). She underwent mediastinoscopy with biopsy of lymph nodes and histopathological examination revealed fibrosis and hyalinised granulomas consistent with sarcoidosis. She was treated with low molecular weight heparin and intravenous steroids which resulted in resolution of her symptoms and clinical signs over the subsequent week. Oral anticoagulants and corticosteroids were continued as an outpatient. A thrombophilia screen performed 16 weeks after the thrombosis revealed normal protein $\mathrm{C}$ and $\mathrm{S}$ levels, normal antithrombin III levels, and testing for the lupus anticoagulant was negative.

This is the first report to our knowledge of sarcoidosis presenting as upper extremity deep vein thrombosis, although a recent case reported in Thorax described a patient with tuberculous mediastinal lymphadenopathy associated with pulmonary artery occlusion. In addition to venous compression by enlarged lymph nodes, possible contributing factors in our patient include the use of the

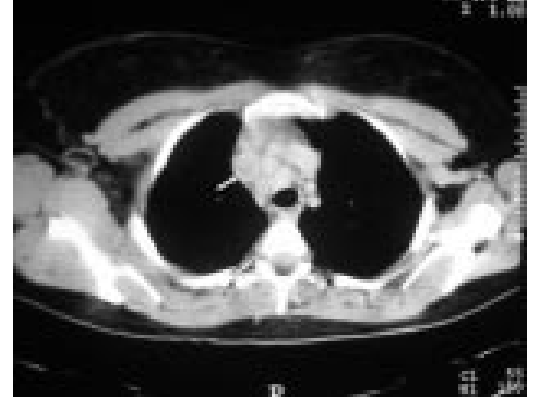

Figure 1 CT scan of thorax showing thrombosed right brachiocephalic vein as indicated by arrow and mediastinal lymphadenopathy.

oral contraceptive pill, cigarette smoking and obesity, all of which have been associated with an increased risk of venous thromboembolic disease related to venous stasis and/or altered coagulation. Upper extremity thrombosis due to venous compression from enlarged mediastinal lymph nodes is usually associated with malignant lymphadenopathy. However, the present report shows that benign mediastinal lymphadenopathy, such as that associated with sarcoidosis, also has the potential to cause venous thrombosis.

A M McLaughlin, W T McNicholas Department of Respiratory Medicine, St Vincent's University Hospital, Dublin 4, Ireland walter.mcnicholas@ucd.ie

\section{References}

1 Drake WM, Elkin SL, Al-Kutoubi A, et al. Pulmonary artery occlusion by tuberculous mediastinal lymphadenopathy. Thorax 1997:52:301-2

\section{Genotype-phenotype correlations in PCD patients carrying DNAH5 mutations}

Primary ciliary dyskinesia (PCD) is usually inherited as an autosomal recessive disorder. Affected individuals suffer from recurrent infections of the upper and lower respiratory tract due to reduced mucociliary clearance. Half of the affected offspring exhibit a complete situs inversus because of randomisation of left-right body asymmetry. ${ }^{12}$ The PCD phenotype results from axonemal abnormalities in cilia and flagella. Total or partia absence of dynein arms are found in $70-80 \%$ of PCD cases.

PCD represents a heterogeneous group of genetic disorders. Distinct PCD loci have been mapped to chromosome 9p13-p2l (DNAII), 19q13.3-qter and 5p15-pl4, respectively. ${ }^{4-6}$ We identified DNAH5 as the gene responsible for PCD located on 5p. DNAH5 encodes a protein highly similar to the Chlamydomonas $\gamma$-dynein heavy chain. ${ }^{6}$ Mutants of the Chlamydomonas orthologue show a slow swimming phenotype and are characterised by axonemal abnormalities consisting of outer dynein arm (ODA) defects. ${ }^{78}$ This phenotype appears similar to that observed in a large Arab family 

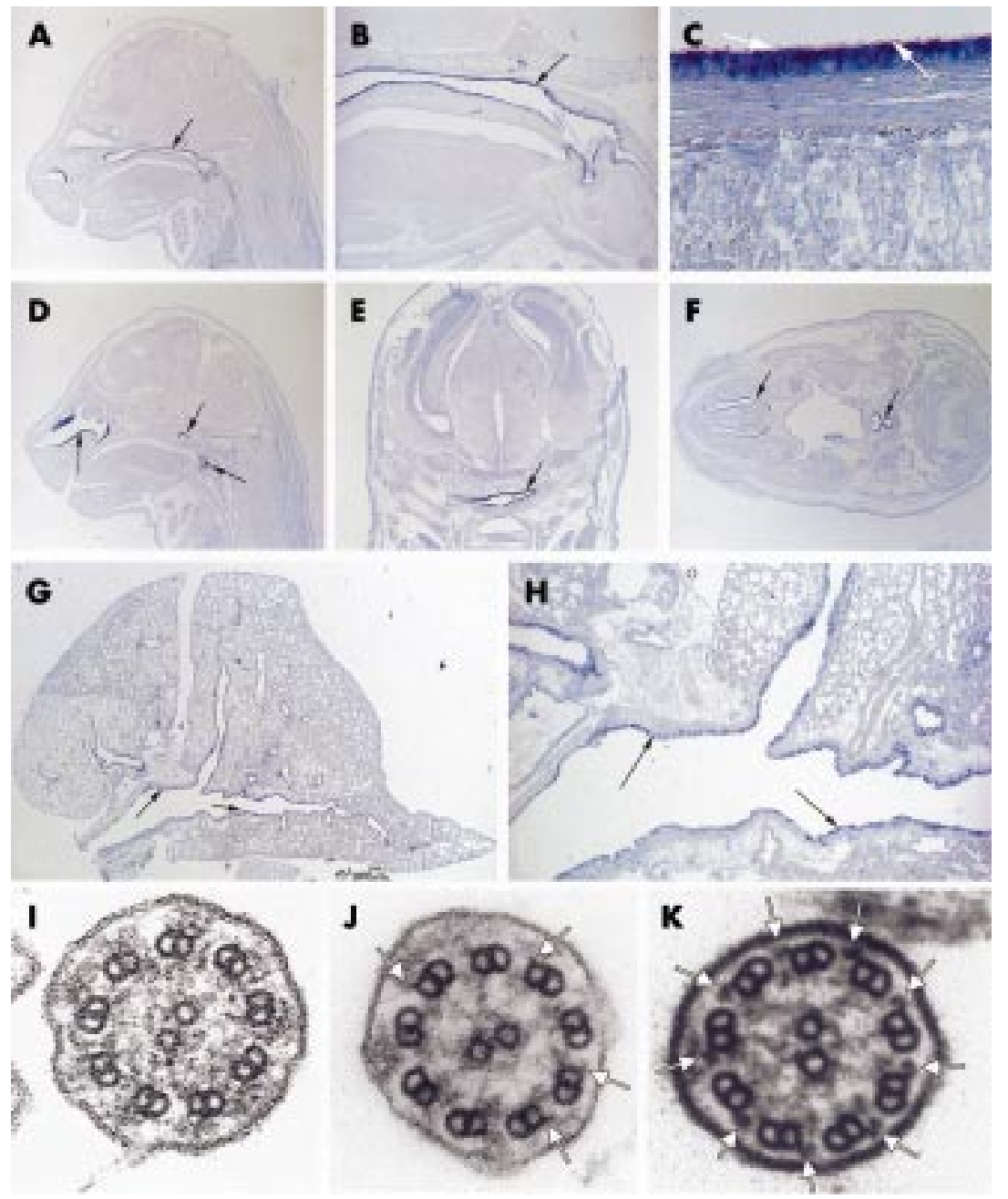

Figure 1 In situ hybridisation analysis of mouse Dnahc5 expression in the developing and adult respiratory system and ultrastructural defects in patients with PCD carrying DNAH5 mutations. (A)-(F) Section in situ hybridisation analysis of Dnahc5 expression in mouse 16 days post coitum embryos. Photographs show details of expression in the nasopharynx, larynx and trachea, respectively. Note cilia on epithelial cells in $C$ (white arrows). (G), (H) Section in situ hybridisation analysis of Dnahc5 expression in mouse adult lung. Note epithelial expression in the whole bronchial system. (I) Electron micrograph of a cross section of a respiratory cilium from an affected individual from PCD family F658. Absence of outer dynein arms (ODA) is observed on all of the nine peripheral doublets. (J) Electron micrograph of a cross section of a cilium from the respiratory epithelium of an affected individual of PCD family UNC-7. The number of visible ODA on the peripheral doublets is reduced. The remaining ODA are shorter (arrows). (K) Electron micrograph of a cross section of a respiratory cilium from a healthy individual (control). Arrows indicate the location of ODA.

used to map the PCD locus. ${ }^{6}$ Sequence analysis of the DNAH5 gene in PCD patients with randomisation of left-right asymmetry identified mutations resulting in non-functional DNAH5 proteins. ${ }^{9}$

The murine orthologue of human DNAH5, called Dnahc5, is predominantly expressed in the lung as shown by Northern blot analysis. During gastrulation expression is confined to the node, which explains the randomisation of left-right asymmetry in PCD. Mice with a targeted mutation in Dnahcs display a phenotype highly similar to that observed in patients with PCD. ${ }^{10}$ Dnahcs deficient mice develop respiratory symptoms due to reduced mucociliary clearance, and half of the affected offspring have complete situs inversus.

In order to gain insight into the development of the disease phenotype and the function of DNAH5, we have studied the expression of Dnahc5 in the murine respiratory tract in both embryonic and adult tissue of mice using section in situ hybridisation analysis as described previously. ${ }^{9}$ We found that Dnahc5 expression is confined to ciliated epithelial cells of the upper and lower airways (fig $\mathrm{lA}-\mathrm{H})$. This expression pattern is consistent with the PCD phenotype of humans resulting from mutations in DNAH5 and mice with a targeted disruption of Dnahc5, respectively. ${ }^{9}$ Our expression data strongly suggest that ultrastructural abnormalities resulting from DNAH5 mutations should be present in ciliated respiratory epithelia of the nasopharynx, the larynx, and the bronchi. Sampling of respiratory cilia at different sites of the airway should not therefore affect ultrastructural findings caused by DNAH5 mutations.

Individuals of different PCD families exhibit various degrees of respiratory symptoms. We hypothesised that the severity of the disease phenotype might correlate with the molecular nature of the DNAH5 mutation in a family. Ultrastructural analysis of respiratory cilia in three families carrying homozygous mutations of DNAH5 indicated such a genotype-phenotype correlation. Electron microscopic photographs of respiratory cilia from families F373 and F658 have been reported previously and were compared with ultrastructural findings of the UNC-7 family. ${ }^{70}$ Mutations causing premature translational termination of DNAH5 (1855NfsX5, 2814fsX1) result in a complete absence of all ODA in respiratory cilia (fig II-K). In contrast, a splice site mutation predicting a loss of exon 75 (IVS74-1G $>$ C) did not cause total absence of ODA. We semiquantitatively assessed ciliary axonemes from the affected siblings of UNC-7 for the presence of ODA in a blinded manner ( $n=36$ cilia for one sibling, $n=9$ from the other). ${ }^{11}$ Both siblings had shortened stubby ODA compared with normal. Computer aided quantitative measurement showed that $54 \%$ of the ODA were less than half the average length of ODA in normal subjects, which indicates partial ODA deficiency.

We provide evidence for the first genotypephenotype correlation in PCD. DNAH5 mutations should be considered in individuals with total and partial absence of ODA.

\section{Acknowledgement}

We are grateful to the patients and their families for their participation in this study. This work was supported by the German Research Foundation (DFG) grant Om 6/2-1, Braun Foundation, and UNC grants RR00046 and NIH HL 04225.

A Kispert, M Petry

Medizinische Hochschule Hannover, Germany

H Olbrich, A Volz, U-P Ketelsen, J Horvath, R Melkaoui, H Omran Department of Pediatrics and Adolescent Medicine, Freiburg, Germany

M Zariwala, P G Noone, M Knowles University of North Carolina at Chapel Hill, NC-27599, USÁ

Correspondence to: Dr H Omran, Department of Pediatrics and Adolescent Medicine, Mathildenstrasse 1, 79106 Freiburg, Germany; omran@kikli.ukl.uni-freiburg.de

\section{References}

1 Afzelius BA. A human syndrome caused by immotile cilia. Science 1976;193:317-9.

2 Afzelius BA, Mossberg B. Immotile cilia syndrome (primary ciliary dyskinesia) including Kartagener syndrome. In: Scriver $\mathrm{CR}$, Beaudet AL, Sly WS, eds. The metabolic and molecular bases of inherited disease. New York: McGraw-Hill, 1995: 3943-54.

3 Jorissen $M$, Willems T, Van der Schueren BR, et al. Ultrastructural expression of primary ciliary dyskinesia after ciliogenesis in culture. Acta Otorhinolaryngol Belg 2000;54:343-56.

4 Pennarun G, Escudier E, Chapelin C, et al. Loss-of-function mutations in a human gene related to Chlamydomonas reinhardtii dynein IC78 result in primary ciliary dyskinesia. Am J Hum Genet 1999;65:1508-19.

5 Meeks M, Walne A, Spiden S, et al. A locus for primary ciliary dyskinesia maps to chromosome 19q. J Med Genet 2000;37:241-4.

6 Omran H, Häffner K, Völkel A, et al. Homozygosity mapping of a gene locus for primary ciliary dyskinesia on chromosome $5 p$ and identification of the heavy dynein chain DNAH5 as a candidate gene. Am J Respir Cell Mol Biol 2000;23:669-702.

7 Rupp G, O'Toole E, Gardner LC, et al. The sup-pf-2 mutations of Chlamydomonas alter the activity of the outer dynein arms by 
modification of the gamma-dynein heavy chain. J Cell Biol 1996;135: 1853-65.

8 Wilkerson CG, King SM, Witman GB.

Molecular analysis of the gamma heavy chain

of Chlamydomonas flagellar outer-arm dynein

J Cell Sci 1994;107:497-506.
9 Olbrich $\mathbf{H}$, Häffner K, Kispert A, et al. Mutations in DNAH5 cause primary ciliary dyskinesia and randomization of left-right asymmetry. Nature Genet 2002;30:143-4.

10 Ibanez-Tallon I, Gorokhova S, Heintz N. Loss of function of axonemal dynein Mdnah5 causes primary ciliary dyskinesia and hydrocephalus. Hum Mol Genet 2002;11:715-21.

11 Sannuti A, Zariwala MA, Daines CL, et al. Quantification of outer and inner dynein arms in primary ciliary dyskinesia (PCD). Am J
Respir Crit Care Med 2000;161:A129.

\section{Clinical Evidence-Call for contributors}

Clinical Evidence is a regularly updated evidence based journal available worldwide both as a paper version and on the internet. Clinical Evidence needs to recruit a number of new contributors. Contributors are health care professionals or epidemiologists with experience in evidence based medicine and the ability to write in a concise and structured way.

Currently, we are interested in finding contributors with an interest in the following clinical areas:

Altitude sickness; Autism; Basal cell carcinoma; Breast feeding; Carbon monoxide poisoning; Cervical cancer; Cystic fibrosis; Ectopic pregnancy; Grief/bereavement; Halitosis; Hodgkins disease; Infectious mononucleosis (glandular fever); Kidney stones; Malignant melanoma (metastatic); Mesothelioma; Myeloma; Ovarian cyst; Pancreatitis (acute); Pancreatitis (chronic); Polymyalgia rheumatica; Post-partum haemorrhage; Pulmonary embolism; Recurrent miscarriage; Repetitive strain injury; Scoliosis; Seasonal affective disorder; Squint; Systemic lupus erythematosus; Testicular cancer; Varicocele; Viral meningitis; Vitiligo

However, we are always looking for others, so do not let this list discourage you.

Being a contributor involves:

- Appraising the results of literature searches (performed by our Information Specialists) to identify high quality evidence for inclusion in the journal.

- Writing to a highly structured template (about 2000-3000 words), using evidence from selected studies, within 6-8 weeks of receiving the literature search results.

- Working with Clinical Evidence Editors to ensure that the text meets rigorous epidemiological and style standards.

- Updating the text every eight months to incorporate new evidence.

- Expanding the topic to include new questions once every 12-18 months.

If you would like to become a contributor for Clinical Evidence or require more information about what this involves please send your contact details and a copy of your CV, clearly stating the clinical area you are interested in, to Claire Folkes (cfolkes@bmigroup.com).

\section{Call for peer reviewers}

Clinical Evidence also needs to recruit a number of new peer reviewers specifically with an interest in the clinical areas stated above, and also others related to general practice. Peer reviewers are health care professionals or epidemiologists with experience in evidence based medicine. As a peer reviewer you would be asked for your views on the clinical relevance, validity, and accessibility of specific topics within the journal, and their usefulness to the intended audience (international generalists and health care professionals, possibly with limited statistical knowledge). Topics are usually 2000-3000 words in length and we would ask you to review between 2-5 topics per year. The peer review process takes place throughout the year, and our turnaround time for each review is ideally 10-14 days.

If you are interested in becoming a peer reviewer for Clinical Evidence, please complete the peer review questionnaire at www.clinicalevidence.com or contact Claire Folkes (cfolkes@bmigroup.com). 